Article

\title{
Effect of Compound Biochar Substrate on the Root Growth of Cucumber Plug Seedlings
}

\author{
Guoxin Ma ${ }^{1,2}$, Hanping Mao 1,2,*, Quan Bu ${ }^{1}$, Luhua Han ${ }^{1,2}$, Abdul Shabbir ${ }^{1}$ and Feng Gao ${ }^{1}$ \\ 1 School of Agricultural Engineering, Jiangsu University, Zhenjiang 212013, China; \\ 2111716008@stmail.ujs.edu.cn (G.M.); qbu@ujs.edu.cn (Q.B.); hanlh@ujs.edu.cn (L.H.); \\ Abdulshabbir@uaf.edu.pk (A.S.); jams280757070@gmail.com (F.G.) \\ 2 Key Laboratory of Modern Agricultural Equipment and Technology, Ministry of Education, \\ Jiangsu University, Zhenjiang 212013, China \\ * Correspondence: maohp@ujs.edu.cn; Tel.: +86-1351-169-5868
}

Received: 6 July 2020; Accepted: 24 July 2020; Published: 26 July 2020

\begin{abstract}
Since plug seedling plays a key role in automatic transplanting, this work aimed to explore the effect biochar has on the root growth of plug seedlings. The physicochemical properties tests showed that the addition of biochar in the peats could increase the porosity, $\mathrm{pH}$, and $\mathrm{EC}$ values of the substrate, and the substrates treated with $0 \%, 10 \%, 20 \%$, and $30 \%$ biochar could meet the requirements of seedling raising. The water retention of the substrate was superior with the increase of biochar proportion, and the nitrogen release significantly decreased with the increase of the biochar proportion. Our results demonstrated that the substrate with $10 \%$ biochar-treated apparently promoted the growth of seedlings and root systems, even the length of the root-tip cells. However, the substrates with $40 \%$ and $50 \%$ biochar-treated obviously inhibited the growth of seedlings and root systems. It was noticed that the strength of substrate with appropriate biochar proportion was enhanced, as well. Under the interaction of strong root system and solid substrate, the compressive strength of the substrate with $20 \%$ and $10 \%$ biochar-treated was much better than others, especially that of $40 \%$ and $50 \%$ biochar-treated, which efficiently satisfied the requirements of automatic seedling picking. The biochar may have a good application prospect in seedling raising.
\end{abstract}

Keywords: substrate; tests; root system; seedling picking; economic benefit

\section{Introduction}

Seedling transplanting technology can extend the growth period of crops and significantly increase the yield, and about half of the cash crops use this technology now [1]. The automatic pick-up device has developed rapidly in order to cooperate with seedling transplanting technology to achieve higher economic benefits. However, most of the pick-up devices are still in the experimental stage because the mechanical characteristic of the seedling is difficult to meet the requirements of automatic seedling picking [2-4]. Besides, the success ratio of seedling picking is low and the seedling substrate is easily damaged during the seedling picking process if the mechanical characteristic of the seedling is not good, especially when picking at a high speed, so it is important to cultivate the seedlings with good mechanical properties which can meet the requirements of the high-speed picking $[5,6]$.

In order to solve this problem, researchers and scientists have made great efforts in this area. Yang proposed that root system was the key to bind loose substrate and also the main stress object in the process of seedling picking [2], and Ting suggested that adding rock wool with better fiber structure into substrate would improve the binding ability of root system [7]. Petronela mixed the secondary cellulosic fibers, peat, and additives as the substrate to raise the seedlings, which promoted the growth of root system and enhanced the mechanical properties of the substrate [8]. In order to 
reduce the seedling damage in the process of mechanical transplanting, Kumar used the paper pot to raise the seedling, which was composed of $25 \%$ vermicompost and $75 \%$ soil and sand [9]. By using the substrate based of peatmoss and coir, Min found that peatmoss could improve the cohesion of root system and substrate [10]. Different from other scholars, Qu used the hydrolyzed soy protein modified urea formaldehyde resins as the substrate, which could promote root growth and ensure the mechanical properties of the substrate at the same time [11], but this research used a chemical way to forcibly bond the substrate, which lacked the test of adaptability to automatic seedling picking.

Biochar is a carbon-rich product obtained by pyrolysis of corncob, straw, peanut shell and other biomass [12,13], and it is a good medium for soil improvement, which can promote the growth of plants [14]. Previous studies pointed out that biochar had the following remarkable functions: (1) It can reduce soil density and bulk density [15], (2) it can improve soil $\mathrm{pH}$ [16] and enhance the cation exchange capacity (CEC) in soil [17], (3) it can improve soil porosity, so as to enhance water and fertilizer conservation performance $[18,19],(4)$ it has a large specific surface area, so the $\mathrm{C} / \mathrm{N}$ ration of soil will be increased, so as to improve the absorption capacity of nitrogen and other nutrient elements [20,21], and the large surface area will promote the growth of microorganisms [22]. Today, most of the substrate used for plug seedling raising were composed of peat, vermiculite and perlite, and previous research proposed that this kind of substrate had relatively good mechanical properties [23], but the cost of this substrate was high and some farmers were reluctant to use this substrate. Li's research proposed that the application of a certain proportion of biochar in the soil can promote the growth of cucumber root system [24]. The results that biochar promoted plant growth, however, were all from field experiments, while few experiments were done to explore whether biochar can promote the growth of seedlings which raised in the plug tray.

In view of the various excellent characteristics of biochar, pine-wood derived biochar was prepared via pyrolysis, and the influence of the prepared biochar existing substrate on promoting the root growth of plug seedlings was investigated. Besides, we will carry out the experiments to test the plug seedlings which were raised by the mixed substrates and find out the appropriate proportion of the substrate considering the requirements of seedling picking and production cost. This research will provide some basis for the current automatic seedling picking technology.

\section{Materials and Methods}

\subsection{Materials}

The crops tested in this study are "Jinyou 1" cucumber seedling (provided by cucumber research institute in Tianjin Academy of Agricultural Sciences, Tianjin, China), the substrate used in this study is composed of peat, vermiculite, perlite, and self-made biochar in a certain proportion, and the seedlings are raised in the 72-hole plastic plug tray widely used in China now. Pine pellet was purchased from Tianxu Energy Co., Guangzhou, China.

\subsection{Preparation of the Biochar}

Pine pellet was used as feedstock. The biochar was pyrolyzed by a tube furnace reactor, and a certain amount of pine pellet was added to the quartz boat; nitrogen was purged for $15 \mathrm{~min}$ at a flow rate of $50 \mathrm{~mL} / \mathrm{min}$ before the reaction so as to obtain an oxygen free condition; the pine pellet was heated from room temperature to $550{ }^{\circ} \mathrm{C}$ at a heating rate of $55^{\circ} \mathrm{C} / \mathrm{min}$ and then held at $550{ }^{\circ} \mathrm{C}$ for $1 \mathrm{~h}$, and nitrogen was purged throughout the process. Biochar was obtained when the reaction temperature decreased to room temperature.

\subsection{Preparation of the Substrates}

The previous substrate was mixed with peat, vermiculite, and perlite in the proportion of 3:1:1 [23], and then mixed with the prepared biochar as the new substrate. As shown in Supplementary Figure S1, preliminary tests showed that too much biochar would inhibit the growth of crops (the substrate was 
composed of $100 \%$ biochar, and the seedling had been growing for 15 days), so the following substrate mixtures were used: previous substrate with $0 \%$ biochar-treated (as a control group), 10\% biochar-treated, 20\% biochar-treated, 30\% biochar-treated, 40\% biochar-treated, and 50\% biochar-treated by weight, and the substrate with different proportions were represented by $T_{0}, T_{1}, T_{2}, T_{3}, T_{4}$, and $T_{5}$, respectively.

\subsection{Physicochemical Properties of the Substrates}

Determination of bulk density: After the substrates prepared with different proportions were configured, samples were taken immediately with the ring cutter, and we weighed the ring cutter filled with the substrate as soon as possible. At the same time, the aluminum box was used for sampling in the same substrate to determine the mass moisture content, so we can easily get the bulk density as

$$
\mathrm{BD}=\frac{m_{1}-m_{2}}{V \cdot(1+\omega)}
$$

where BD means bulk density, $\mathrm{g} / \mathrm{cm}^{3} ; m_{1}$ is the weight of ring cutter filled with the substrate, $\mathrm{g} ; m_{2}$ is the weight of the ring cutter, $g$; $V$ is the volume of ring cutter, $\mathrm{cm}^{3}$; and $\omega$ is the mass water content of the substrate sample, $\mathrm{g} / \mathrm{kg}$.

Determination of porosity: firstly, a certain amount of the prepared substrate was weighed after being soaked in the water for $24 \mathrm{~h}$; then we put the wet substrate in the gauze, and let it drain freely for $24 \mathrm{~h}$, after that, we moved it from the gauze and weighed it; finally, the substrate was put into the oven to dry to constant weight at $105^{\circ} \mathrm{C}$, so we got the porosity as

$$
\left\{\begin{array}{c}
A P=\frac{W_{1}-W_{2}}{V} \times 100 \% \\
W P=\frac{W_{2}-W_{3}}{V} \times 100 \% \\
P=A P+W P \\
V R=\frac{A P}{W P}
\end{array},\right.
$$

where $A P$ is aeration porosity; $W P$ is water-holding porosity; $P$ is whole porosity; $V R$ is void ratio; $W_{1}$ is the weight of the sample which was soaked for $24 \mathrm{~h}, \mathrm{~g} ; W_{2}$ is the weight of the sample which was drained freely for $24 \mathrm{~h}, \mathrm{~g} ; W_{3}$ is the weight of the sample which was baked into a constant weight, $\mathrm{g}$; and $V$ is the volume of the sample, $\mathrm{g} / \mathrm{cm}^{3}$.

Determination of $\mathrm{pH}$ and EC value: $50 \mathrm{~g}$ substrate was taken out as a sample from each substrate, which was crushed and put into the breaker; then, distilled water was used to wet the sample to keep their water content around 55\%. After placing the sample for $24 \mathrm{~h}$, we weighed $25 \mathrm{~g}$ wet sample in the beaker and poured in $50 \mathrm{~mL}$ distilled water; then, we put the beaker into the oscillator and let it work for $1 \mathrm{~h}$, after which we filtered the sample to get the filtrate, where AZ-8601 and AZ-8303 (RS232) were used to determine the $\mathrm{pH}$ and $\mathrm{EC}$ values of the substrate, respectively.

\subsection{Water Retention and Nitrogen Release of the Substrates}

Previous research showed that water and nutrients were two important factors which would affect the growth of the plants [25], so some tests were arranged to find out the water retention and nitrogen release of the new substrate. In order to ensure the accuracy of the test, the incubator with constant temperature, illumination and humidity (Supplementary Figure S2b; made by Shuolian Co., Hangzhou, China) was used for cultivation in this research. Previous study also showed that the suitable temperature for cucumber growth was $18 \sim 28^{\circ} \mathrm{C}$, the illumination which the cucumber seedling needed every day must be $8 \sim 10 \mathrm{~h}$, and the humidity should be controlled at 60 80\% [26], so we set the parameters of the incubator as shown in Supplementary Figure S2c. Based on $24 \mathrm{~h}$ a day, parameters were set in two stages: day and night. The time period marked 01 simulated the day stage, the temperature was set to $25^{\circ} \mathrm{C}$, the light intensity was level 3 , and the duration of illumination was $11 \mathrm{~h}$; The time period marked 02 simulated the night stage, the temperature was set to $20^{\circ} \mathrm{C}$, the light intensity was level 0 , and the duration was $13 \mathrm{~h}$. 
Determination of the water retention: The seedlings used in our research were raised in the plastic plug trays, in order to simulate the change of water content during the actual growth of seedlings as much as possible; we filled the new substrate with a certain quality into the plug tray to determine its water retention. The 72-hole plug tray was divided into three parts, and each part has 18 holes. As shown in Supplementary Figure S2a, we filled same quality substrates with different treatment into each hole and weighed the quality of each part separately, put them into the water to absorb enough water and weighed each part again, and, finally we put them into the incubator for cultivation. After that, we measured the weight of each sample once every day and repeated twenty times, so as to calculate the water retention of substrate in different proportion.

Determination of the nitrogen release: the soil column leaching method [27] and UDK 159 automatic Kjeldahl azotometer (made by VELP Co., Milan, Italy) were used in the experiment. We chose transparent PVC pipe with the height of $300 \mathrm{~mm}$ and the diameter of $40 \mathrm{~mm}$ as the leaching column, and 150 mesh nylon net was used to seal the bottom of PVC pipe. By using quartz sand as leaching medium, we added $60 \mathrm{~mm}$ quartz sand $(1 \mathrm{~mm} 2 \mathrm{~mm})$ at the bottom of the pipe; then, we mixed $20 \mathrm{~g}$ substrate sample with $20 \mathrm{~g}$ quartz sand and added them into the pipe, after which we added $10 \mathrm{~mm}$ quartz sand again to prevent the disturbance of substrate layer when leaching, and, finally, we poured $50 \mathrm{~mL}$ distilled water into the pipe and sealed the top of the pipe by polyethylene film with some $1 \mathrm{~mm}$ holes. Besides, we also set a sample without substrate as a control (CK marked in Supplementary Figure S3a), and three repetitions were set for each sample, and all leaching columns were placed in the incubator (Supplementary Figure S2b) with $25^{\circ} \mathrm{C}$ constant temperature treatment during the whole experiment. The leaching columns would be taken out on the 1st, 5 th, 9 th, 13 th, 17th, and 21th day, respectively, and washed with $100 \mathrm{~mL}$ distilled water; then, $25 \mathrm{~mL}$ leaching liquid was collected and put into the centrifuge tube for total nitrogen determination. The steps of total nitrogen determination were as follows: first, $2 \mathrm{~mL}$ leaching liquid was taken out from the centrifuge tube and put into the digester tube [28]; second, $4 \mathrm{~g}$ catalyst ( $100 \mathrm{~g} \mathrm{~K}_{2} \mathrm{SO}_{4}+10 \mathrm{~g} \mathrm{CuSO} 45 \mathrm{H}_{2} \mathrm{O}+1 \mathrm{~g} \mathrm{Se}$ ) and $5 \mathrm{~mL}$ concentrated sulfuric acid were poured into the digester tube to mix with the leaching liquid; third, the digester tube was put in the digestion furnace for digestion; finally, the total nitrogen content in the leaching liquid was determined by automatic Kjeldahl azotometer (Supplementary Figure S3b).

\subsection{Cultivation and Growth of the Seedlings}

As well as putting the selected cucumber seeds in each hole of the tray, the substrates were filled with different treatment and put into six 72-hole plug trays according to the requirements of seedling cultivation [23]; after the substrates in each plug tray absorbed enough water, they were put into the incubator (Supplementary Figure S2b); all parameters were set according to Supplementary Figure S2c.

Cucumber seedlings were found to germinate in about three days, so the growth data of seedlings were measured from the seventh day after germination in order to get more accurate data, and then measured every four days, four times in total. The measurement methods of each index are as follows: (1) Emergence ratio, the proportion of the seedling emergence in one plug tray; (2) plant height, the distance from the surface of substrate to the highest growth point of the seedling, which was measured by ruler $(0.1 \mathrm{~mm})$ (Supplementary Figure S4a); (3) leaf exhibition, the distance between the tips of two leaves (Supplementary Figure S4b); (4) and root dry matter, the substrate in the seedling was washed completely and only retained the root system (Supplementary Figure S4c); then the absorbent paper was used to absorb excess water and put in the oven which was set at $105^{\circ} \mathrm{C}$ for $15 \mathrm{~min}$, after which the temperature would be reset to $80^{\circ} \mathrm{C}$, followed by keeping drying until the weight was constant; finally, precision electronic scale $(0.0001 \mathrm{~g})$ was used to get the weight of root dry matter.

\subsection{Root System Analysis of the Seedlings}

Physical parameters of roots: The length, diameter of main root, surface area, volume, and tip number of root system were mainly measured in this study. We used protective cleaning method [29] 
to wash and tidy the root system, then chose the Perfection V700 photo scanner (made by EPSON Co., Nagano, Japan) to scan the roots (Supplementary Figure S5b), and the WinRHIZO root analysis software (professional version) was used to process the root data.

Length of root-tip cells: In order to better display the growth of root system, histological method was used to analyze the root system and measure the length of root cells. First, we selected the suitable small root-tips from the washed roots, and the root-tips were made into paraffin block by paraffin embedding method, so that the root cell structure would not be destroyed (Supplementary Figure S5c); then, the paraffin blocks were put into the slicer to get the appropriate cell sample, and the cell sample was dyed by using saffron and fast green according to plant root-tip cell standard dyeing process; finally, we chose VHX-900F Superdepth Microscope (made by KEYENCE Co., Osaka, Japan) to scale the length of the cell.

Compressive strength: The mechanical properties of plug seedlings are the result of the interaction of root system and substrate, and the substrates with the root system are the main force part during seedling picking. As shown in Supplementary Figure S5a, we chose the WDW350005 electronic universal testing machine to determine the compressive capacity of the plug seedlings (23 days) suitable for transplanting. Actually, the shape of the seedling was similar to trapezoid cone platform, so a specially designed clamping apparatus was made to ensure that the pressed surface of the seedling was in horizontal state. Besides, Micro-CT technology was also used to scan and reconstruct the three-dimensional structure of the root system [30] in order to better describe the mechanical properties of the seedling.

\subsection{Data Analysis}

All experimental data were analyzed by using SPSS 23.0 and Excel 2016, and all data graphs were made by Origin 2018. Besides, the least significant difference (LSD) method was used for multiple comparisons of these data, and we used $*(0.01<p<0.05)$ and ${ }^{* *}(p<0.01)$ to indicate whether there was remarkable difference between the different proportion of biochar and the control group $\left(\mathrm{T}_{0}\right.$, $0 \%$ biochar-treated).

\section{Results and Discussion}

\subsection{Effect of Biochar on Physicochemical Properties of the Substrate}

Previous research showed that larger porosity would retain more air and water in the substrate, which could benefit the growth of root system [11]. As shown in Table 1, the addition of biochar significantly reduced the bulk density of the substrate, which resulted in a significant increase for the porosity of the substrate. The reason was that biochar had large specific surface area and porosity (Supplementary Figure S6), which was superior than in common peat, so the mixing of biochar and peat would greatly increase the porosity of substrates.

Table 1. Physicochemical properties of the substrates with different treatment.

\begin{tabular}{cccccccc}
\hline Samples & $\begin{array}{c}\text { Bulk Density/ } \\
\left(\mathbf{g} \cdot \mathbf{c m}^{-3}\right)\end{array}$ & $\begin{array}{c}\text { Aeration } \\
\text { Porosity/\% }\end{array}$ & $\begin{array}{c}\text { Water-Holding } \\
\text { Porosity/\% }\end{array}$ & $\begin{array}{c}\text { Whole } \\
\text { Porosity/\% }\end{array}$ & Void Ratio & pH Value & EC/(mS·cm $\mathbf{- 1})$ \\
\hline $\mathrm{T}_{0}$ & $0.243 \mathrm{a}$ & $43.79 \mathrm{e}$ & $18.89 \mathrm{e}$ & $62.67 \mathrm{f}$ & $0.431 \mathrm{c}$ & $6.02 \mathrm{f}$ & $0.752 \mathrm{f}$ \\
$\mathrm{T}_{1}$ & $0.215 \mathrm{~b}$ & $50.39 \mathrm{~d}$ & $21.94 \mathrm{~d}$ & $72.34 \mathrm{e}$ & $0.435 \mathrm{c}$ & $6.23 \mathrm{e}$ & $0.959 \mathrm{e}$ \\
$\mathrm{T}_{2}$ & $0.2 \mathrm{C}$ & $51.65 \mathrm{c}$ & $23.57 \mathrm{c}$ & $75.23 \mathrm{~d}$ & $0.456 \mathrm{~b}$ & $6.45 \mathrm{~d}$ & $1.008 \mathrm{~d}$ \\
$\mathrm{~T}_{3}$ & $0.185 \mathrm{~d}$ & $52.64 \mathrm{~b}$ & $24.18 \mathrm{c}$ & $76.82 \mathrm{c}$ & $0.459 \mathrm{~b}$ & $6.71 \mathrm{c}$ & $1.047 \mathrm{c}$ \\
$\mathrm{T}_{4}$ & $0.171 \mathrm{e}$ & $53.33 \mathrm{~b}$ & $25.03 \mathrm{~b}$ & $78.36 \mathrm{~b}$ & $0.469 \mathrm{~b}$ & $7.02 \mathrm{~b}$ & $1.128 \mathrm{~b}$ \\
$\mathrm{~T}_{5}$ & $0.159 \mathrm{f}$ & $55.41 \mathrm{a}$ & $27.82 \mathrm{a}$ & $83.24 \mathrm{a}$ & $0.502 \mathrm{a}$ & $7.29 \mathrm{a}$ & $1.175 \mathrm{a}$ \\
\hline
\end{tabular}

Note: The data in the table are the average value of different substrates after repeated processing, and different letters in the same column indicate that the value is significant when $p<0.05$ by least significant difference (LSD) multiple comparison method, the same as below. 
However, the porosity of substrate was not the bigger the better. Xia proposed that the bulk density and porosity of the substrate should be appropriate, so the substrate had the enough aeration porosity for the plants to ensure the efficiency of air exchange, and the water-holding porosity would be suitable at the same time so that the substrate could retain enough water for the plants to absorb [31]. In general, the suitable parameters of substrate for plant growth were bulk density at $0.1 \sim 0.8 \mathrm{~g} / \mathrm{cm}^{3}$, whole porosity at $54 \sim 96 \%$, and void ratio at $0.25 \sim 0.5$ [32]. Based on Table 1, it was apparent that only the void ratio of $T_{5}$ treatment was not within the above requirements.

As shown in Table 1, the addition of biochar significantly increased the $\mathrm{pH}$ and $\mathrm{EC}$ values of the substrate compared with the $\mathrm{T}_{0}$ treatment. Because of the special production process, the biochar was generally alkaline, so the $\mathrm{pH}$ value was higher with the increase of biochar content. Early research showed that the suitable $\mathrm{pH}$ value of substrates for seedling raising should be neutral $(\mathrm{pH}=7)$ or slightly less than 7 [33], so the substrates with $\mathrm{T}_{4}$ and $\mathrm{T}_{5}$ treatments (especially $\mathrm{T}_{5}$ treatment) might reduce the growth of seedlings to some extent. EC value, another index, reflects the concentration of soluble ions in the substrate. Biochar could significantly increase the cation exchange capacity of the substrate, so the EC value of new substrate enhanced with the increase of biochar content. Previous research indicated that nutrition in substrate was not enough to maintain seedling growth if the EC value was too low, and the salt damage would be brought to the seedlings if the EC value was too high, the suitable EC value for seedling raising should be $0.5 \mathrm{mS} / \mathrm{cm} \sim 2.75 \mathrm{mS} / \mathrm{cm}$ [33], so the EC value of all treatments in our research could meet the standard of seedling raising.

\subsection{Determination of Water Retention and Nitrogen Release of the Substrates}

After the substrates with different treatment absorbed enough water, the variation characteristics of water loss on 21 consecutive days were shown in Figure 1a. Actually, the larger the absolute value of the line's slope was, the worse the water retention of the substrates would be.
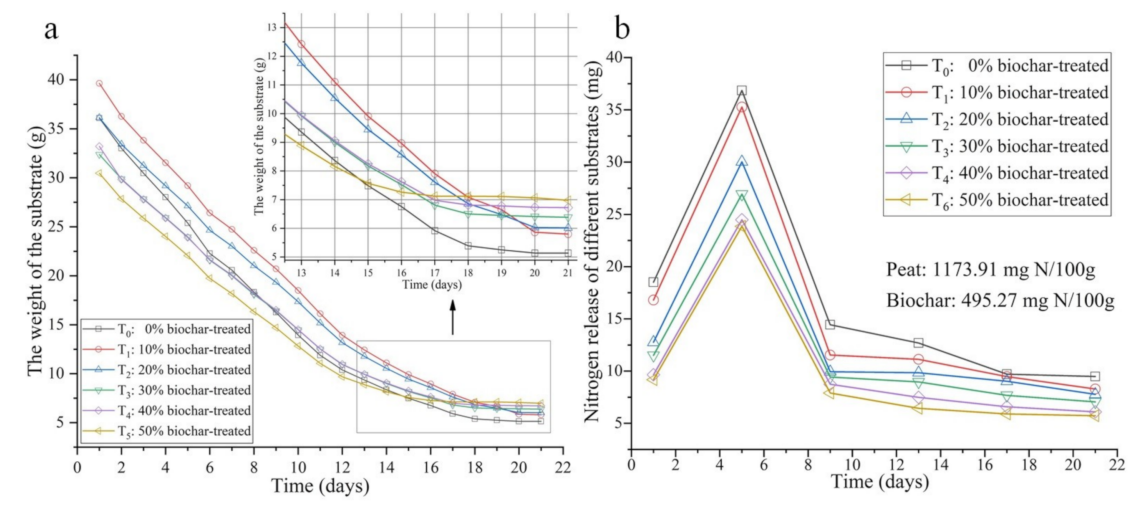

Figure 1. Water retention and nitrogen release of different substrates. (a) Water retention of different substrates; (b) nitrogen release of different substrates.

The absolute value of the line's slope $\left(\mathrm{T}_{0}: 1.81, \mathrm{~T}_{1}: 1.65, \mathrm{~T}_{2}: 1.55, \mathrm{~T}_{3}: 1.43, \mathrm{~T}_{4}: 1.39, \mathrm{~T}_{5}: 1.31\right)$ decreased with the increase of biochar content, which proved that the water retention of the substrate would be better if the proportion of biochar was higher. The reason was that the biochar has porous structure with large porosity, which could better store the water absorbed in the substrate [19], so that the water loss of substrate with biochar would be lower than the substrate without biochar. The average weight of each substrate with different treatment before water absorption in this experiment was $8 \mathrm{~g}$, after absorbing enough water, the heaviest one was the substrate with $\mathrm{T}_{1}$ treatment $(39.637 \mathrm{~g})$, and the lightest one was the substrate with $\mathrm{T}_{5}$ treatment $(30.463 \mathrm{~g}$ ). As shown in the enlarged part of Figure 1a, the first substrate that dropped to $8 \mathrm{~g}$ was $\mathrm{T}_{5}$, and the last was $\mathrm{T}_{1}$, indicating that the substrate with $\mathrm{T}_{1}$ treatment had the best water retention in comparison with the substrates with other treatments. Besides, the substrate's weight from the lightest to the heaviest on the 21th day was $T_{0}, T_{1}, T_{2}, T_{3}, T_{4}$, and $T_{5}$ in sequence, which meant initial moisture content of peat was much better than biochar, so the 
content of biochar in the substrate was not the more the better. To sum up, adding a certain proportion of biochar in the substrate significantly increased the water retention of the substrate.

As shown in Figure 1b, the nitrogen release of the substrates first increased and then decreased along with the increasing of seedling raising days, and the nitrogen release decreased obviously with the increase of biochar content. The nitrogen release of the substrates reached the maximum value on the 5th day, and gradually decreased to a stable level. The nitrogen release of the substrates with $\mathrm{T}_{0}$ and $\mathrm{T}_{1}$ treatment was much more than others, but the nitrogen release of the substrates with $\mathrm{T}_{4}$ and $\mathrm{T}_{5}$ treatment was the least compared with others. The reason was that the biochar had a large specific surface area, which could better absorb the nitrogen and other nutrient elements $[20,21]$, so the nitrogen release would decrease with the increase of the proportion of the biochar in substrate. Besides, the growth cycle of plug seedling for automatic transplanting was generally short ( $20 \sim 25$ days), and the seedlings require enough nutrient to grow, so the growth of plug seedling would be significantly promoted with more nitrogen release in a short time.

\subsection{Effect of Biochar on the Growth of the Seedlings}

As shown in Figure 2a, the growth states showed great differences among 19-day-old cucumber seedlings raised in different substrates, indicating that the proportion of biochar was not the more the better. The substrate with $\mathrm{T}_{1}$ treatment clearly promoted the growth of the seedlings, and the seedling raised in the substrate with $\mathrm{T}_{2}$ treatment was almost the same as that in $\mathrm{T}_{0}$ treatment, but the seedlings raised in the substrates with $\mathrm{T}_{4}$ and $\mathrm{T}_{5}$ treatment were the worst in comparison with that in other treatments, especially the $T_{5}$ treatment. To find out the possible factors of biochar affecting seedling growth, the emergence ratio, plant height and leaf exhibition of the seedlings were measured (Figure 2b-d).

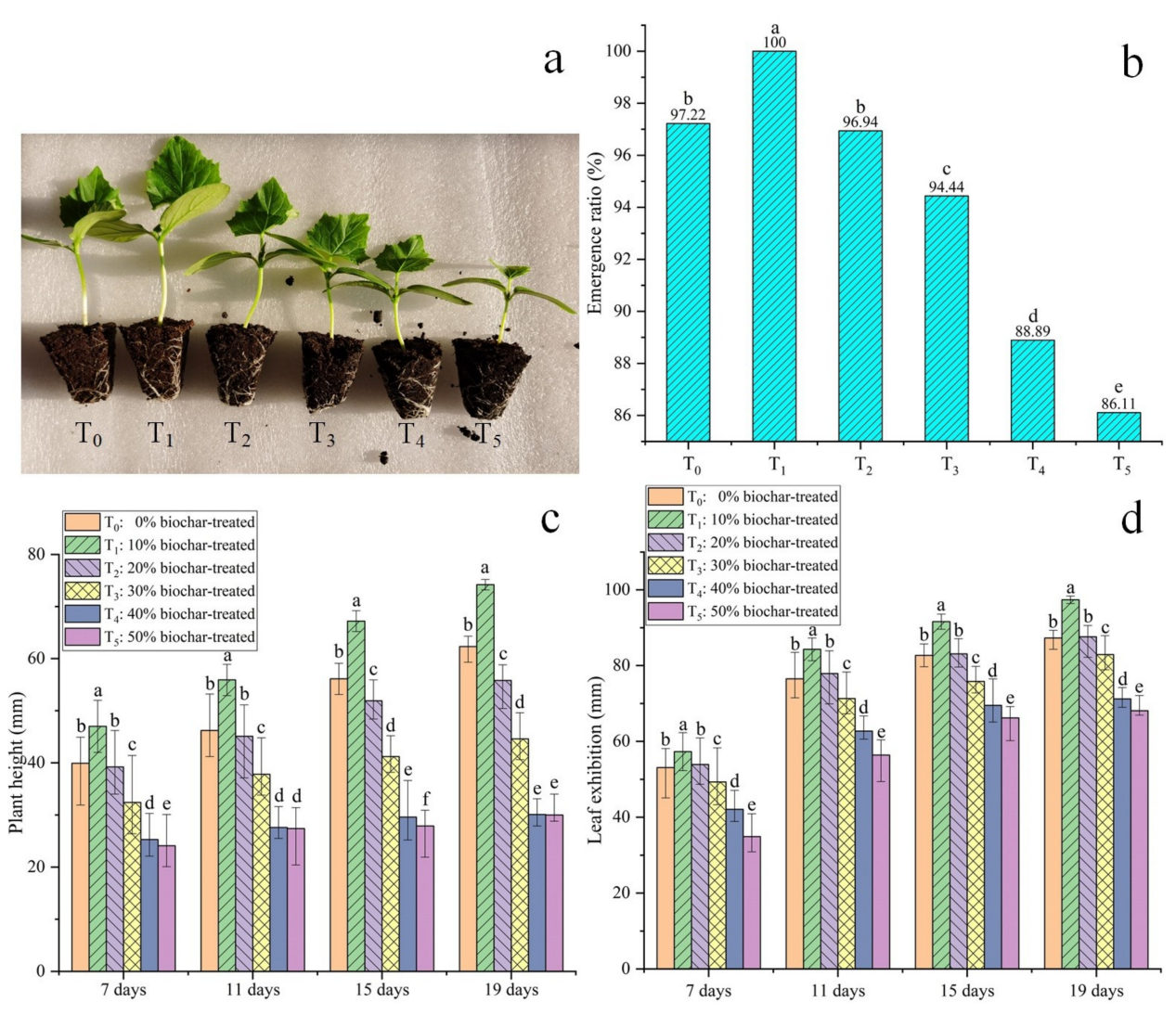

Figure 2. Growth parameters of the seedlings raised in different substrates. (a) Seedlings have been growing for 19 days; (b) emergence ratio of the seedlings; (c) plant heights of the seedlings; (d) leaf exhibitions of the seedlings. 
As shown in Figure $2 \mathrm{~b}$, emergence ratio of the substrate with $\mathrm{T}_{1}$ treatment was much greater than others in this experiment, and all cucumber seeds have sprouted in this substrate. Besides, the emergence ratio of the substrates with $\mathrm{T}_{0}$ and $\mathrm{T}_{2}$ treatment were slightly lower than $\mathrm{T}_{1}$ treatment, $97.22 \%$ and $96.94 \%$, respectively, and almost all the seeds have sprouted in these substrates. However, the emergence ratio just reached $88.89 \%$ and $86.11 \%$, respectively, when the seeds raised in the substrates with $\mathrm{T}_{4}$ and $\mathrm{T}_{5}$ treatment, and these seeds sprouted one or two days later than others.

Plant height was of great importance to the substrate with $\mathrm{T}_{1}$ treatment because the substrate with 10\% biochar-treated resulted in higher plant height compared with other treatments (Figure 2c). The plant height of seedlings raised in the substrates with $T_{0}$ and $T_{2}$ treatment was almost the same at any growth period, and the plant height of seedlings raised in the substrates with $\mathrm{T}_{0}$ treatment was slightly better than that in $\mathrm{T}_{2}$ treatment, but their plant heights were much lower than that in $\mathrm{T}_{1}$ treatment. The plant height of the seedlings, however, raised in the substrates with $T_{4}$ and $T_{5}$ treatment was the worst, and the plant height did not change significantly during the whole test period.

Leaf exhibition (11 19 days) showed a significant difference in the substrate with $\mathrm{T}_{1}$ treatment because seedlings got a longer leaf exhibition in the substrate with $10 \%$ biochar-treated (Figure $2 \mathrm{~d}$ ). The leaf exhibition of seedlings raised in the substrates with $T_{0}$ and $T_{2}$ treatment was almost the same at any growth period, which was much lower than that in $\mathrm{T}_{1}$ treatment. As the proportion of biochar in the substrate increased, the leaf exhibition of seedlings became shorter on the same day, and the leaf exhibition of the seedlings raised in the substrates with $T_{5}$ treatment was the shortest compared with others.

These test results indicated that the substrate with $10 \%$ biochar-treated could significantly promote the growth of seedlings, and seedlings raised in the substrate with $20 \%$ biochar-treated were almost the same as the control group ( $\mathrm{T}_{0}$ treatment). The reason was that the addition of biochar in proper proportion could significantly improve the physicochemical properties of the substrates, and the nitrogen release was much better than others, which could promote the growth of the seedling. The proportion of biochar in the substrate, however, was not the more the better; the seedlings could not grow well, especially when the proportion of biochar in the substrates reached $40 \%$ and $50 \%$. The reason was that some of the physicochemical properties of the substrates with $\mathrm{T}_{4}$ and $\mathrm{T}_{5}$ treatment were not suitable for seedling growth, and the nitrogen release of these two substrates was the least, which was detrimental to the growth of seedlings.

\subsection{Growth Status on the Root System of the Seedlings}

The last experiment confirmed that $10 \%$ biochar-treated had a significant impact on promoting the growth of seedlings, and the parameters of root systems of the seedlings raised in different substrates were shown in Table 2, which also shows a significant difference in the substrate with $\mathrm{T}_{1}$ treatment. The parameters of root systems raised in substrates with $\mathrm{T}_{0}$ and $\mathrm{T}_{2}$ treatment were almost the same and were much lower than that in $\mathrm{T}_{1}$ treatment. Besides, the parameters of root systems raised in substrates with $\mathrm{T}_{4}$ and $\mathrm{T}_{5}$ treatment were the worst compared with that in other treatments.

The total length of the root and the weight of root dry matters were two important parameters to judge root growth [34], so we selected these two parameters in order to better describe the effect of substrates with different biochar treatment to root systems. The root systems of the 19-day-old seedlings were washed carefully, and, finally, the roots were put on the paper after excess water of them was absorbed (Figure 3a). We found that the seedling raised in the substrate with $\mathrm{T}_{1}$ treatment got the strongest root system, and the root system of the seedlings raised in the substrate with $T_{0}$ and $\mathrm{T}_{2}$ treatment were almost the same which were weaker than that in $\mathrm{T}_{1}$ treatment. However, the root system of the seedlings raised in the substrate with $\mathrm{T}_{4}$ and $\mathrm{T}_{5}$ treatment were the worst in comparison with that in other treatments. 
Table 2. Parameters of root systems in the seedlings raised in different substrates.

\begin{tabular}{cccccccc}
\hline \multirow{2}{*}{ Parameters of Root Systems } & Time (Days) & \multicolumn{5}{c}{ Samples } \\
\cline { 2 - 7 } & & $\mathbf{T}_{\mathbf{0}}$ & $\mathbf{T}_{\mathbf{1}}$ & $\mathbf{T}_{\mathbf{2}}$ & $\mathbf{T}_{\mathbf{3}}$ & $\mathbf{T}_{\mathbf{4}}$ & $\mathbf{T}_{\mathbf{5}}$ \\
\hline \multirow{3}{*}{ Total length $(\mathrm{cm})$} & 7 & 41.214 & 47.006 & 39.773 & 35.409 & 30.244 & 28.012 \\
& 11 & 66.030 & 80.251 & 64.187 & 38.065 & 33.063 & 32.319 \\
& 15 & 98.238 & 120.555 & 95.546 & 76.725 & 57.811 & 55.360 \\
& 19 & 121.803 & 142.415 & 119.612 & 85.005 & 70.067 & 69.128 \\
\hline \multirow{2}{*}{ Surface area $\left(\mathrm{cm}^{2}\right)$} & 7 & 4.817 & 5.938 & 4.797 & 4.547 & 3.598 & 3.388 \\
& 11 & 8.773 & 10.006 & 8.365 & 6.839 & 4.486 & 3.957 \\
& 15 & 15.462 & 19.018 & 14.024 & 10.757 & 7.323 & 6.953 \\
Average diameter $(\mathrm{mm})$ & 19 & 20.010 & 24.857 & 19.638 & 13.850 & 8.712 & 8.696 \\
\hline \multirow{2}{*}{ Total volume $\left(\mathrm{cm}^{3}\right)$} & 7 & 0.447 & 0.503 & 0.436 & 0.381 & 0.357 & 0.344 \\
& 11 & 0.506 & 0.594 & 0.480 & 0.426 & 0.405 & 0.386 \\
& 15 & 0.581 & 0.699 & 0.559 & 0.489 & 0.431 & 0.417 \\
& 19 & 0.656 & 0.771 & 0.629 & 0.537 & 0.455 & 0.424 \\
\hline & 7 & 0.061 & 0.0795 & 0.0605 & 0.046 & 0.0345 & 0.033 \\
& 11 & 0.105 & 0.158 & 0.102 & 0.089 & 0.077 & 0.075 \\
& 15 & 0.203 & 0.24 & 0.206 & 0.154 & 0.129 & 0.126 \\
& 19 & 0.254 & 0.295 & 0.241 & 0.205 & 0.168 & 0.157 \\
\hline
\end{tabular}

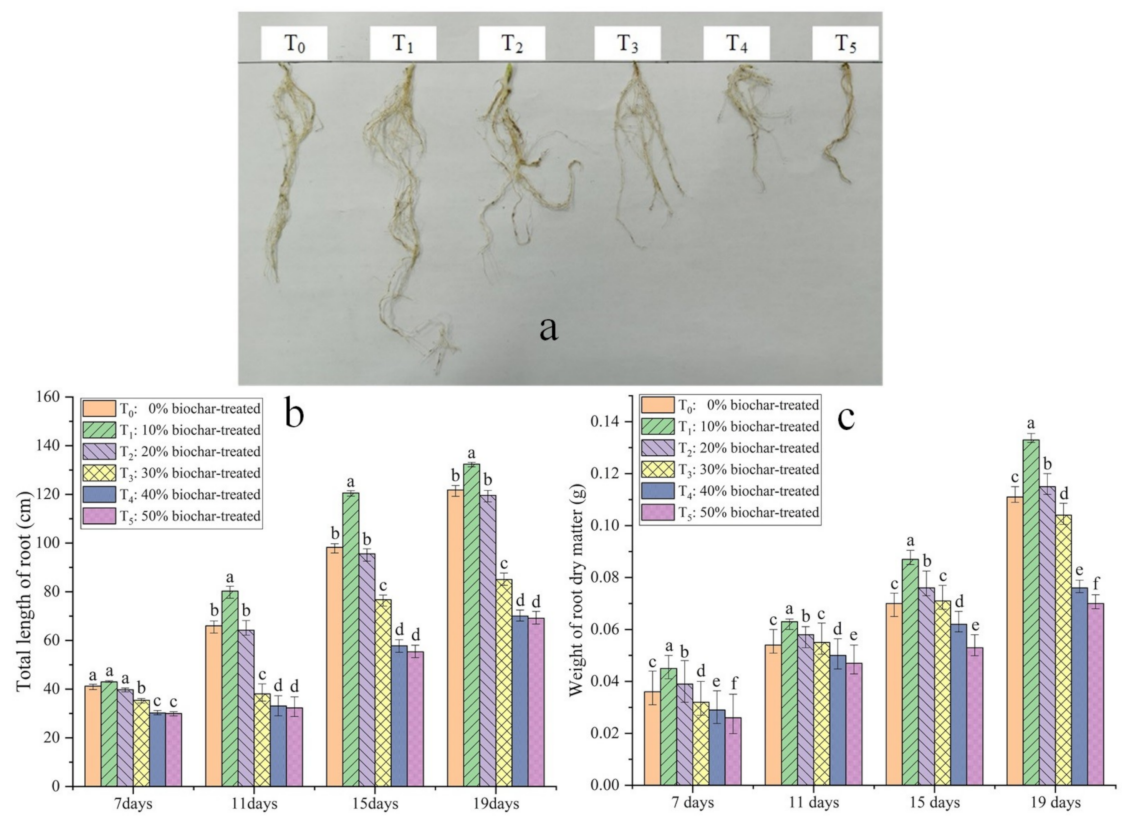

Figure 3. Analysis of the root systems raised in different substrates. (a) Washed roots of the seedlings; (b) total lengths of roots in the seedlings; (c) weight of root dry matters of the seedlings.

As shown in Figure $3 \mathrm{~b}$, the total root length of the seedlings raised in the substrate with $\mathrm{T}_{1}$ treatment (11 19 days) was much better than other treatments, and the total root length of the seedlings was the most obvious on the 15th day. The root length raised in $T_{2}$ treatment was almost the same as that in $\mathrm{T}_{0}$ treatment, and all of them were lower than that in $\mathrm{T}_{1}$ treatment. However, the root length raised in $\mathrm{T}_{4}$ and $\mathrm{T}_{5}$ treatment were much shorter than that in other treatments, which even reduced the growth of the root system compared with $\mathrm{T}_{0}$ treatment. 
As shown in Figure 3c, the weight of root dry matter increased faster as time goes by, and the weight of root dry matter did not show a significant difference between 7th day and 11th day, but the weight of root dry matter raised in $\mathrm{T}_{1}$ treatment was much better than that in other treatments from 15th day, and the weight of root dry matter decreased from $T_{1}$ treatment with the increase of biochar proportion in the same period. Besides, the weight of root dry matter raised in $\mathrm{T}_{2}$ treatment was slightly higher than that in $\mathrm{T}_{0}$ treatment. However, the weight of root dry matter raised in $\mathrm{T}_{4}$ and $\mathrm{T}_{5}$ treatment was the lightest in comparison with that in other treatments, especially on 19th day, which indicated that the substrates with $40 \%$ and $50 \%$ biochar-treated would inhibit the growth of seedling roots.

Yang proposed that a certain proportion of biochar-extracted liquor could also promote the length of the cells [34], so we selected some root-tips to measure the length of the cells by using VHX-900F Superdepth Microscope. As shown in Figure 4a, we took the photo of the root-tip cells at the scale of $100 \mu \mathrm{m}$, randomly selected the cells from five parts, and measured their average length which was shown in Figure $4 \mathrm{~b}$. The seedlings raised in $\mathrm{T}_{1}$ treatment have greatly enhanced the cell length compared with $\mathrm{T}_{0}$ treatment $(P<0.05)$, and the cell length raised in $\mathrm{T}_{2}$ treatment was slightly longer than that in $\mathrm{T}_{0}$ treatment, but cell length raised in the substrates with $\mathrm{T}_{3}, \mathrm{~T}_{4}$, and $\mathrm{T}_{5}$ treatment significantly reduced. This test also proved that appropriate proportion of biochar could promote the growth of seedling's root system.
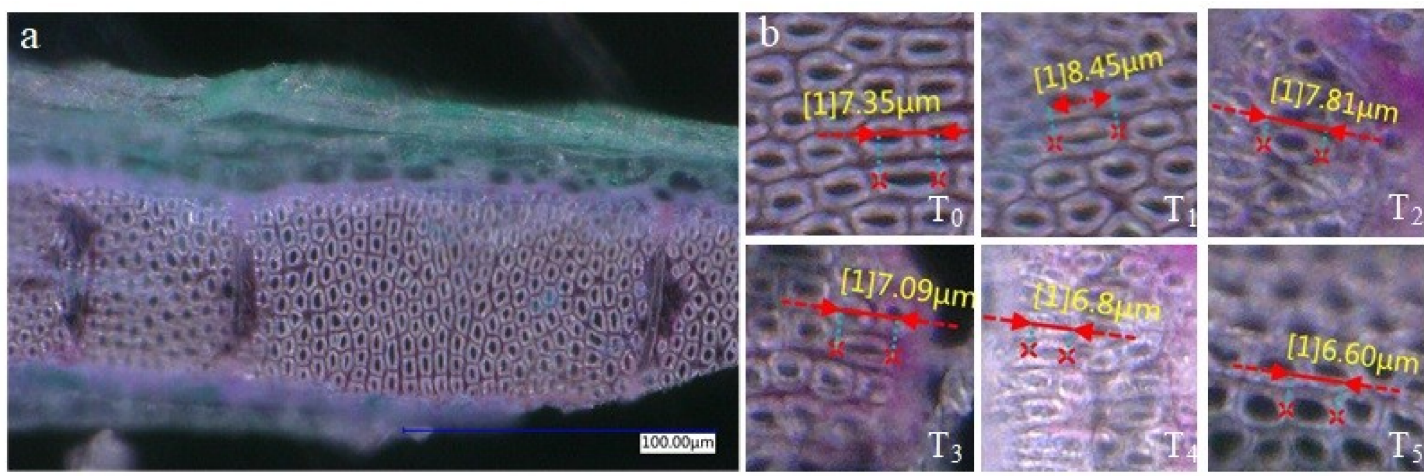

Figure 4. Analysis of root-tip cell length of the seedlings raised in different substrates. (a) Root-tip cells under the microscope at the scale of $100 \mu \mathrm{m}$; (b) different root-tip cell lengths treated with biochar of different proportions.

\subsection{Growth Status on the Root System of the Seedlings}

The end-effector is the main part of the transplanter to realize automatic transplanting, and most end-effectors equipped in the transplanter now are installed with some pins to clamp and pick out the seedlings from the plug tray [6]. Compressive strength of the substrate, as an important index, directly affects the damage rate of plug seedlings [23].

Previous research proposed that the root system could bind the loose substrate together, which was the main stress object when seedling picking [2], so the better root system would bring better compressive strength. In order to better describe the effect on compressive strength of substrates with different biochar-treated, Micro-CT technology was used to restructure the 3D image of the root systems. The seedlings, as shown in Figure 5, raised in the substrates with $\mathrm{T}_{0}, \mathrm{~T}_{1}$, and $\mathrm{T}_{2}$ treatment had better root structures, and the root systems were strong enough to grow around the substrate, so the substrate could be bound more tightly by the root system. The seedlings raised in the substrates with $\mathrm{T}_{3}, \mathrm{~T}_{4}$, and $T_{5}$ treatment, however, got poor root structures, and there was no root in some locations of the substrate, so the root systems were weak and the substrate would be loose. 

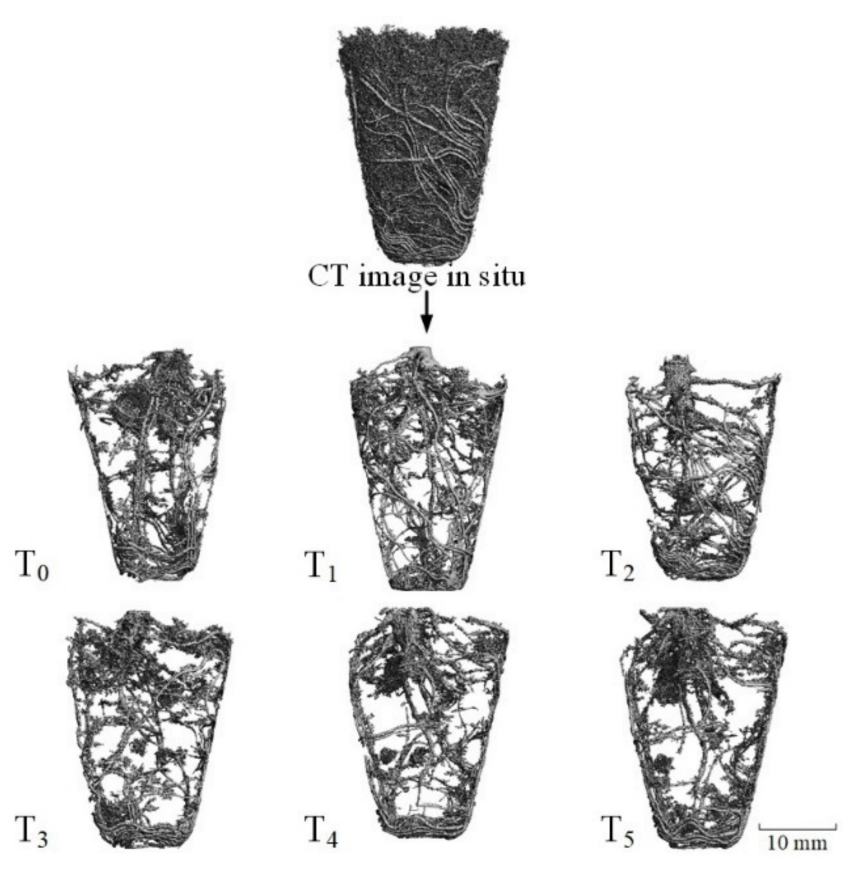

Figure 5. Three-dimensional reconstruction image of the root system.

As shown in Figure 6, different proportions of biochar could greatly affect the compressive strength of the substrate. Zhang proposed that the addition of biochar could highly improve the mechanical properties of the compound body [35]; thus, theoretically, adding more biochar could bring better mechanical properties to the substrate, but the mechanical property should be the result of the interaction of substrate and root system.

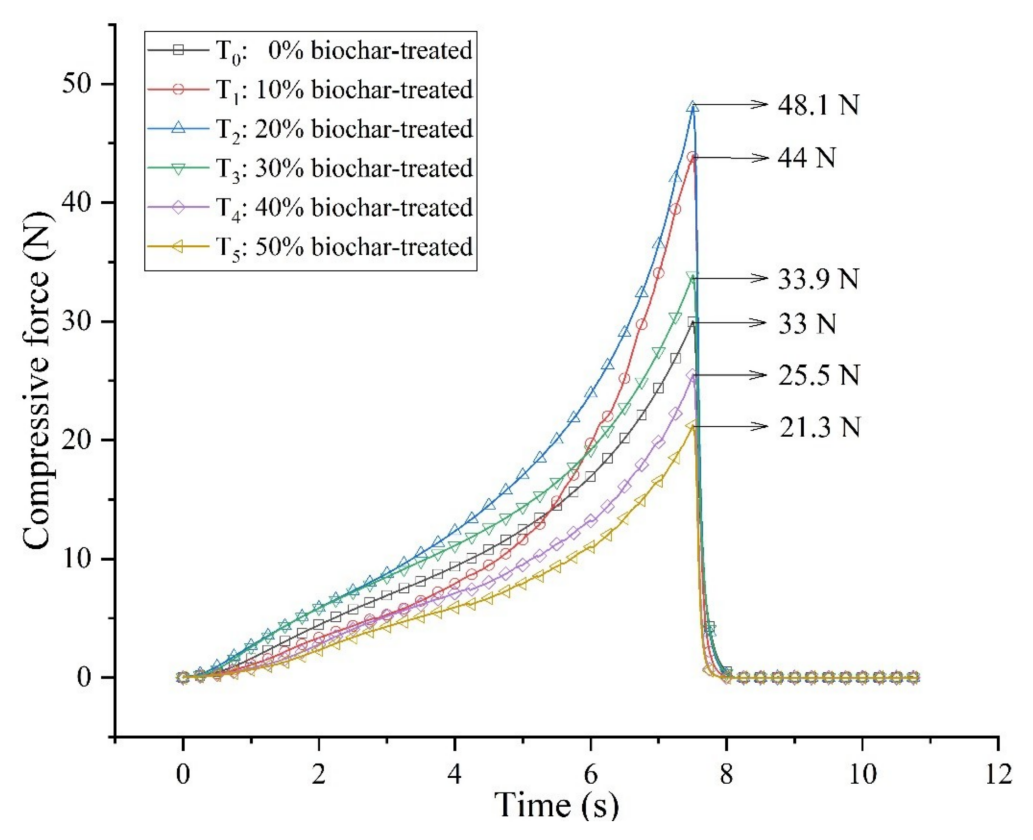

Figure 6. Compressive strength of the seedlings raised in different substrates.

The substrate with $\mathrm{T}_{2}$ treatment got the best compressive strength $(48.1 \mathrm{~N})$, and compressive strength of the substrate with $\mathrm{T}_{1}$ treatment $(44 \mathrm{~N})$ was slightly lower than that in $\mathrm{T}_{2}$ treatment, which was much greater than other substrates. The reason was that the root system was strong enough to bind the substrate tightly in both seedlings raised in the substrate with $\mathrm{T}_{1}$ and $\mathrm{T}_{2}$ treatment, and the 
addition of the biochar could enhance the mechanical property of the substrate, so the compressive strength of these two substrates was better than that of other substrates. Besides, the proportion of biochar in the substrate with $\mathrm{T}_{2}$ treatment was more than that in $\mathrm{T}_{1}$ treatment, so the compressive strength of the substrate with $\mathrm{T}_{2}$ treatment was better than that in $\mathrm{T}_{1}$ treatment. Although the root system in the substrate with $\mathrm{T}_{0}$ treatment was strong, too, the compressive strength was just $33 \mathrm{~N}$, which was even a bit lower than the substrate with that in $\mathrm{T}_{3}$ treatment $(33.9 \mathrm{~N})$ without the addition of the biochar. When the proportion of biochar in the substrate reached $40 \%$ and $50 \%$, the compressive strength decreased to the minimum value $25.5 \mathrm{~N}$ and $21.3 \mathrm{~N}$, respectively. The reason was that although the proportion of the biochar in these substrates was large, the root systems in the substrates with $\mathrm{T}_{4}$ and $\mathrm{T}_{5}$ treatment were really weak, so the substrate could not be bound tightly, which resulted in poor compressive strength. To sum up, the substrates with $\mathrm{T}_{1}$ and $\mathrm{T}_{2}$ treatment could bring better compressive strength to the seedlings, which met the requirements of the end-effectors to clamp and pick the seedlings.

\section{Conclusions}

On the basis of seedling raised by substrate with peats, we attempted to find out the effect of the biochar added in peats on the growth of seedlings by testing the properties of the substrates, growth status of the seedlings, parameters of root systems, and compressive strength of the substrates. With the addition of biochar, the $\mathrm{pH}$ and EC value of the substrate increased significantly, as well as the aeration porosity and the water holding porosity of the substrate. The analysis showed that the substrates with $0 \%, 10 \%, 20 \%$, and 30\% biochar-treated could theoretically meet the requirements of seedling raising, but the substrates with $40 \%$ and $50 \%$ biochar-treated reduced the growth of the seedlings to some extent. The water retention of the substrates could significantly increase with the addition of a certain proportion of biochar in the substrate, and the nitrogen release would obviously decrease with the increase of the biochar in the substrate. The growth test results indicated that the substrate with $10 \%$ biochar-treated could evidently promote the plant and root growth, even the length of the root-tip cell, but the substrate would inhibit the growth of the seedlings with the increase of biochar proportion, especially when the biochar proportion reached $40 \%$ and $50 \%$. Under the joint action of strong root system and solid substrate, the compressive strength of the substrates with $20 \%$ and $10 \%$ biochar-treated was much better than the substrates with other treatment, which well met the requirements of the seedling picking by the effectors. However, the compressive strength of the substrates with $40 \%$ and $50 \%$ biochar-treated were the worst in comparison with that in other treatments. To sum up, a certain proportion of biochar could not only promote the growth of plug seedlings but also enhance the strength of the substrate, and it may have a good application prospect in seedling raising.

Supplementary Materials: The following are available online at http://www.mdpi.com/2073-4395/10/8/1080/s1, Figure S1: The seedling raised in 100\% biochar, Figure S2: The cultivation of the substrates, Figure S3: Determination of nitrogen by soil column leaching method, Figure S4: Determination of the seedling growth parameters, Figure S5: Analysis of the root system, Figure S6: Surface characteristics of substrate under the microscope.

Author Contributions: Conceptualization, G.M., H.M, and Q.B.; methodology, G.M., H.M., and Q.B.; software, A.S.; validation, H.M. and Q.B.; formal analysis, G.M., Q.B. and L.H.; investigation, F.G.; resources, Q.B.; data curation, G.M.; writing_original draft preparation, G.M.; writing-review and editing, G.M., H.M., Q.B. and A.S.; supervision, H.M. and Q.B.; project administration, H.M.; funding acquisition, H.M. All authors have read and agreed to the published version of the manuscript.

Funding: This research was funded by a grant from the National Key Research and Development Program of China (2017YFD0700800), the Jiangsu Province Science and Technology Support Program of China (No. BE2017303), the Priority Academic Program Development of Jiangsu Higher Education Institutions (PAPD-2018-87), and the Jiangsu Synergy Innovation Center Program of Modern Agricultural Equipment and Technology (4091600005).

Acknowledgments: The author would like to thank the Key Laboratory of Agricultural Engineering in Jiangsu University for supporting the experimental conditions of the research.

Conflicts of Interest: The authors declare no conflict of interest. 


\section{References}

1. Xia, G.; Han, C.; Guo, H.; Zhang, J.; Xu, Y. Research Status and Development Trend of Key Components of Automatic Transplanting Machine. J. Agric. Mech. Res. 2019, 41, 1-7.

2. Yang, Y.; Ting, K.C.; Giacomelli, G.A. Factors affecting performance of sliding-needles gripper during robotic transplanting of seedlings. Trans. Asae 1991, 7, 493-498. [CrossRef]

3. Hula, P.; Sindelr, R.; Trinkl, A. Verification of applicability of ABB robots for trans-planting seedlings in greenhouses. Res. Agric. Eng. 2008, 54, 155-162. [CrossRef]

4. Han, L.; Mao, H.; Hu, J.; Miao, X.; Tian, K.; Yang, X. Experiment on mechanical property of seedling pot for automatic transplanter. Trans. Csae 2015, 29, 24-26.

5. Shaw, L.N. Changes needed to facilitate automatic field transplanting. Hort Technol. 1993, 3, 418-420. [CrossRef]

6. Han, L.; Kumi, F.; Mao, H.; Hu, J. Design and tests of a multi-pin flexible seedling pick-up gripper for automatic transplanting. Appl. Eng. Agric. 2019, 35, 949-957. [CrossRef]

7. Ting, K.C.; Giacomelli, G.A.; Shen, S.J. Robot workcell for transplanting of seedlings: Part II-end-effector development. Trans. Asae 1990, 33, 1013-1017. [CrossRef]

8. Petronela, N.; Elena, D.; Florin, C.; Elena, B. The biodegradability and mechanical strength of nutritive pots for vegetable planting based on lignocellulose composite materials. Bioresources 2010, 5, 1102-1113.

9. Kumar, G.V.P.; Raheman, H. Identification of optimum combination of proportion of vermicompost in the soil-based potting mix and pot volume for the production of paper pot seedlings of vegetables. J. Plant. Nutr. 2012, 35, 1277-1289. [CrossRef]

10. Min, B.; Ha, L.; Lee, J.; Choi, S.; Lee, S. The selection proper materials to develop specialized root substrate for working with bulbonion transplanter. Prot. Hortic. Plant. Fact. 2016, 25, 100-105. [CrossRef]

11. Qu, P.; Cao, Y.; Wu, G.; Tang, W.; Xia, L. Preparation and properties of coir-based substrate bonded by modified urea formaldehyde reinsnfor seedlings. Bioresources 2018, 13, 4332-4345. [CrossRef]

12. Chen, W.; Xu, Z. Researches on biochar application technology. Eng. Sci. 2011, 13, 83-89.

13. Lehmann, J.; Joseph, S. Biochar for environmental management: Science, technology and implementation. Sci. Technol. Earthscan 2015, 25, 15801-15811.

14. Chan, K.Y.; Van Zwieten, L.; Meszaros, I.; Downie, A.; Joseph, S. Using poultry litter biochars as soil amendments. Aust. J. Soil Res. 2008, 46, 437-444. [CrossRef]

15. Major, J.; Rondon, M.; Molina, D.; Riha, S.J.; Lehmann, J. Maize yield and nutrition during 4 years after biochar application to a colombian savanna oxisol. Plant. Soil 2010, 333, 117-128. [CrossRef]

16. Zwieten, L.V.; Kimber, S.; Morris, S.; Chan, K.Y.; Downie, A.; Rust, J. Effects of biochar from slow pyrolysis of papermill waste on agronomic performance and soil fertility. Plant Soil 2010, 327, 235-246. [CrossRef]

17. Liang, B.L.; Lehmann, J.; Solomon, D.; Kinyangi, J.; Neves, E.G. Black carbon increases cation exchange capacity in soils. Soil Sci. Soc. Am. J. 2006, 70, 1719-1730. [CrossRef]

18. Spokas, K.A.; Koskinen, W.C.; Baker, J.M.; Reicosky, D.C. Impacts of woodchip biochar additions on greenhouse gas production and sorption/degradation of two herbicides in a minnesota soil. Chemosphere 2006, 77, 574-581. [CrossRef]

19. Lu, Y.; Wu, P.; Chen, X.; Wang, Y.; Zhao, X. Effect of above-and below-ground interactions on maize/soybean intercropping advantage. Trans. Csam 2014, 45, 143-148.

20. Warnock, D.D.; Lehmann, J.; Kuyper, T.W.; Rillig, M.C. Mycorrhizal responses to biochar in soil-Concepts and mechanisms. Plant Soil 2007, 300, 9-20. [CrossRef]

21. Kimetu, J.M.; Lehmann, J. Stability and stabilisation of biochar and green manure in soil with different organic carbon contents. Aust. J. Soil Res. 2010, 48, 577. [CrossRef]

22. Knoblauch, C.; Maarifat, A.A.; Pfeiffer, E.M.; Haefele, S.M. Degradability of black carbon and its impact on trace gas fluxes and carbon turnover in paddy soils. Soil Biol. Biochem. 2011, 43, 1768-1778. [CrossRef]

23. Miao, X.; Mao, H.; Han, L.; Sun, H.; Yang, X. Analysis of Influencing Factors on Force of Picking Plug Seedlings and Pressure Resistance of Plug Seedlings. Trans. Csam 2013, 44, 27-32.

24. Li, F.; Li, M.; Liu, J.; Hu, Y.; Zhang, Q.; Zhao, H. Effect of Biochar on Fungal Abundance of Rhizosphere Soil and Cucumber Root Growth in Greenhouse. Trans. Csam 2017, 48, 265-271. 
25. Tracy, S.R.; Black, C.R.; Roberts, J.A.; Mooney, S.J. Exploring the interacting effect of soil texture and bulk density on root system development in tomato (solanum lycopersicum L.). Environ. Exp. Bot. 2013, 91, 38-47. [CrossRef]

26. Zhao, H. Growth habit and fertilizer requirement of the cucumber. Farmers Consult. 2018, 24, 37.

27. Song, B.; Sun, R.; Liang, H.; Hu, Y.; Peng, P.; She, D. Effects of Lignin and Biochar Addition on Soil Nitrogen and Phosphorus Nutrients and Water Loss. J. Soil Water Conserv. 2019, 33, 227-232, 241.

28. Bao, G.; Xu, Y.; Yang, L.; Ya, M.; Qian, J. Research and popularization of instrumental method for determination of total nitrogen in soy sauce. J. Light Ind. 2018, 34, 107-108, 172.

29. Wen, W.; Guo, X.; Zhao, C.; Wang, C.; Xiao, B. Crop roots configuration and visualization: A review. Sci. Agric. Sin. 2015, 48, 436-448.

30. Liu, Y.; Mao, H.; Han, L.; Xu, J.; Ma, G. Plug damage detection and parameter optimization of picking up cucumber seedlings from tray cells based on Micro-CT. Trans. Csae 2018, 34, 27-34.

31. Dai, X.; Sun, W.; Fan, Q.; Luo, P.; He, J. Physicochemical property of mixed substrates with agricultural and forestry wastes and comprehensive evaluation of their effect on growth of Camellia oleifera seedlings. J. Plant Resour. Environ. 2016, 25, 54-61.

32. Zhang, S.; Yu, H.; Jiang, W. Seedling effects of corncob and bagasse composting substrates in cucumber. Trans. Csae 2015, 31, 236-242.

33. Kang, H.; Zhang, Q.; Tang, J. Research Advances on Growth Media. Chin. J. Soil Sci. 2005, 36, $124-127$.

34. Yang, E.; Meng, J.; Hu, H.; Cheng, D.; Zhu, C.; Chen, W. Effects of organic molecules from biochar-extracted liquor on the growth of rice seedlings. Ecotoxicol. Environ. Saf. 2019, 170, 338-345.

35. Zhang, Q.; Xu, H.; Ren, X.; Lu, W.; Liu, H.; Zhou, L.; Cai, H.; Yi, W. Preparation and properties of agroforestry wastes biochar/high density polyethylene composites. Acta Mater. Compos. Sin. 2020, 1-9. [CrossRef]

(C) 2020 by the authors. Licensee MDPI, Basel, Switzerland. This article is an open access article distributed under the terms and conditions of the Creative Commons Attribution (CC BY) license (http://creativecommons.org/licenses/by/4.0/). 